\title{
La presión fiscal del siglo XVII en el reino de Murcia: viejas y nuevas figuras tributarias
}

\author{
Francisco Vel.asco Hernández *
}

\section{RESUMEN}

Aunque es un hecho admitido el incremento de la presión fiscal en Castilla durante el sigio XVII, también es cierto que en diferentes zonas la escalada impositiva fue desmesurada, especialmente en el reino de Murcia y Andalucia (paralela a su crecimiento económico). Con esta aproximación al tema hemos analizado el impacto de algunas rentas, antiguas y de nueva creación, sobre los diferentes territorios del reino de Murcia (sobre todo en el puerto de Cartagena), y su incidencia como freno secular al desarrollo.

\begin{abstract}
Although the tax increase in Castilla during the XVII century is a well acknowledged fact, it is also true that in different areas, the tax increment was exhorbitant in the Kingdom of Murcia and Andalucia (parallel to its economical growth). With this approach to the topic, we have analyzed the impact of both new and old taxes on the different territories of the Kingdom of Murcia (especially in the harbour of Cartagena) and its impaci on the secular development restraint there.
\end{abstract}

Desde finales de la Edad Media había quedado institucionalizado buena parte del entramado fiscal castellano sobre la base de una preponderancia mayoritaria de los impuestos indirectos, entre los cuales, las alcabalas, las tercias y los tributos aduaneros interiores (los «puertos

* Universidad de Murcia. 
secos») y exteriores (almojarifazgos, diezmos de la mar...) constituían los recursos más saneados de la Hacienda regia.

Se trata de un proceso de estabilización arancelaria que se inicia en los reinados de Juan $\mid I$ y de los Reyes Católicos ${ }^{1}$ y que culmina a fines del siglo XVI con la creación de los primeros «millones" de Felipe $\|^{2}$. El sistema fiscal así heredado parecía ser suficiente para atender las vastas necesidades del Estado. Sin embargo, la política imperial de los Habsburgo españoles y su intervencionismo en Europa, en un momento en el que la actividad bélica se extendía en varios frentes, supondrá un enorme lastre que será imposible soportar. La solución será, una vez confirmada la disminución constante de las remesas de oro y plata indianas, la presión fiscal in crescendo, que se tornará asfixiante en las décadas centrales del siglo XVII.

Nadie escapará a esta escalada impositiva, que afectará de diversas maneras a todas las regiones. Pero el tratamiento de unas áreas a otras diferirá mucho, dispensando a unas y castigando a otras. En este último caso las comarcas litorales castellanas sufrirán una enorme persecución tributaria ante el convencimiento general (en especial por parte del Consejo de Hacienda) de una mayor prosperidad y riqueza que el interior. El reino de Murcia y, sobre todo, el puerto de Cartagena, van a constituir en este sentido un ejemplo paradigmático.

En el presente artículo pretendemos llevar a cabo una aproximación a las figuras tributarias más importantes que gravaban la actividad de los murcianos del siglo XVII, deteniéndonos en el análisis de algunos de los viejos tributos (alcabalas, tercias, moneda forera y servicio ordinario y extraordinario), así como de las nuevos recursos hacendísticos que se introducen en el reinado de Felipe IV (annatas, donativos y ventas de cargos y oficios).

\section{ALCABALAS Y TERCIAS}

La alcabala constituía el tributo indirecto más representativo de la Hacienda castellana. Con claro origen hispano-musulmán (al-qabala = la gabela), la alcabala gravaba todas las cosas muebles, inmuebles y semo-

Ladero Quesada, M. A., La Hacienda Real de Castilla en el siglo xv. La Laguna, 1973. Idem.: El siglo xv en Castilla: fuentes de renta y política fiscal. Barcelona, 1982; y Ídem.: Legislación hacendistica de la Corona de Castilla en la Baja Edad Media. Madrid, 1999.

UlloA, M., La Hacienda Real de Castilla en el reinado de Felipe 1I. Madrid, 1977; ForteA Pérez. J. I., Monarquía y Cortes en la Corona de Castilla: las ciudades ante la política fiscal de Felipe II. Salamanca, 1990. 
vientes que se vendian o intercambiaban en una comunidad, repercutiendo claramente sobre la actividad comercial. Según Modesto Ulloa, constituía, junto con las tercias, el grupo más importante de los ingresos del rey - hasta la introducción de los Millones-, siendo una de sus características la generalidad, si bien predominaban los impuestos ad-valorem sobre las compraventas o sobre un estimado del valor de las mercancías, con una cuota legal del $10 \%{ }^{3}$. Suponía, por consiguiente, un saneado recurso para la Monarquía, que periódicamente renovaba en Cortes a través de los "encabezamientos generales del reino", fórmula que desde 1536 fue perpetuándose como más válida y eficaz, aunque a la larga provocaría la petrificación de estas rentas en muchas ciudades y pueblos de Castilla.

Junto a las alcabalas se recaudaban también las tercias reales sobre el diezmo eclesiástico, que aparecían unidas en los encabezamientos, si bien se trataba de dos contribuciones de naturaleza diferente, ya que la alcabala era un impuesto sobre las transacciones, mientras que las tercias gravaban la producción de granos, vinos y menudos. Las tercias, a pesar de su nombre, sólo suponían para el fisco real una participación de dos novenos en el producto de todos los diezmos cobrados por la Iglesia. Con ese abono se relacionan también las cargas de trigo que en los días del encabezamiento general recogían los asentistas de la Corona de lo que se debía al rey en concepto de tercias ${ }^{4}$. El hecho de que se arrendaran juntas formando parte uniforme de los encábezamientos hace difícil cuantificar la magnitud de una y otra renta, de ahí que en casos como el de Murcia o Lorca resulta prácticamente imposible evaluar el alcance numérico de las tercias reales. Pero a diferencia de las anteriores, Cartagena no tenía tercias reales, toda vez que habían sido concedidas por privilegio de Fernando III a su obispado. Lo que si parece posible es que las tercias de Murcia y Lorca se redujeran a una contribución fija en especie: 370 fanegas de trigo, la primera, y 130 , la segunda, que eran las cantidades anuales que se entregaban junto con el dinero producido por las alcabalas ${ }^{5}$.

\footnotetext{
Ulloa, M., La Hacienda Reai..., pág. 171.

CARANDE, R., Carlos $V$ y sus banqueros. Barcelona, 1977, págs. 234-235.

5 Esas cantidades representarían los $2 / 9$ del $10 \%$ de unas 16.750 fanegas de trigo producidas por Murcia y su partido en un año, y las 6.000 fanegas de trigo anuales que se recogerían en Lorca. Los medievalistas murcianos han sido los que más se han ocupado de la temática fiscal, si bien todos ellos hablan de imposibilidad a la hora de distinguir numéricamente entre las alcabalas y las tercias en la cucta global resultante (MENJOT, D., Fiscalidad y sociedad. Los murcianos y el impuesto en la Baja Edad Media. Murcia, 1986, pág. 141, y Veas ARTESEROs, C., Fiscalidad concejil en la Murcia de fines del Medievo. Murcia, 1991). Tampoco la historiografía lorquina aporta ninguna luz al respecto (Jiménez AlcázAR, J.F., Lorca a finales de la Edad Media. Murcia, 1992, pág.
} 
Las ciudades y villas del reino de Murcia entrarían en la dinámica de los encabezamientos desde las primeras décadas del siglo XVI, iniciando una trayectoria secular que se prolongará, con la excepción de Cartagena y alguna otra, a lo largo de toda la etapa de los Austrias. La tendencia general será hacia el crecimiento constante de la presión fiscal, sobre todo en Cartagena y Murcia, reservando un trato más benigno al resto del reino murciano (por ejemplo, a Lorca y su comarca). Con todo, el reino de Murcia será duramente castigado. Sin embargo, no todos los lugares de Castilla fueron medidos de la misma forma. Hoy en día sabemos que a muchas localidades del interior les fueron concedidas rebajas, tanto en sus encabezamientos de alcabalas, tercias y cientos, como en el pago de los millones. Otras muchas congelaron e incluso disminuyeron su contribución ${ }^{6}$.

Pero la nota general fue el incremento constante de la presión fiscal, especialmente en Andalucía, reino de Murcia y algunas ciudades del interior, como Madrid o Valladolid. Las autoridades municipales eran conscientes de que se estaba produciendo un proceso de generalización e incremento de la acción tributaria que, de momento, era imposible frenar. En este sentido, el realengo murciano nos ofrece un claro ejemplo de evolución alcista en su contribución por vía de alcabalas, si bien en el caso de Lorca la tendencia final fue hacia el estancamiento e incluso a la disminución de su carga tributaria.

Como puede verse, los datos aportados por el cuadro $n .^{\circ} 1$ son más que elocuentes, sobre todo en el caso cartagenero. De todas formas, es

\section{CUADRO 1}

Valores de alcabalas en las ciudades murcianas de realengo, 1587-1667. (Valor liquido e índice. En maravedies)

\begin{tabular}{|c|c|c|c|c|c|c|}
\hline Lugar & 1587 & 1611 & 1628 & 1650 & \multicolumn{2}{|c|}{ 1667/Balance } \\
\hline Murcia & 12.700 .000100 & $\begin{array}{lll}13.390 .500 & 105,4\end{array}$ & $14.117 .500 \quad 111,1$ & $\begin{array}{lll}15.047 .732 & 118,4\end{array}$ & 9.744 .000 & $-23,2 \%$ \\
\hline Lorca & 3.640 .134100 & $3.008,424 \quad 82,6$ & $2.552 .863 \quad 70,1$ & $2.464 .836 \quad 67,7$ & 2.679 .932 & $-26,3 \%$ \\
\hline Cartagena & 1.800 .00100 & $3.327 .000 \quad 184,8$ & $4.353 .000 \quad 241,8$ & $\begin{array}{lll}5.000 .000 & 277,7\end{array}$ & 4.632 .189 & $+256 \%$ \\
\hline
\end{tabular}

Fuente: A.G.S. Cont. Grles. y Tesoro (Elaboración propia).

43). El único que aborda someramente el tema es $\mathrm{F}$. Chacón al distinguir en un cuadro la renta de las tercias mayores y las rentas de las tercias menores, correspondientes a 1507 y 1511 (CHACÓN JIMEENEZ, F., "Una contribución al estudio de las economías municipaies en Castilla. La coyuntura económica concejil murciana en el periodo 1496-1517", en Miscelánea Medieval Murciana, vol. III, 1977, pág. 227).

6 Dominguez Ortiz, A., Politica y hacienda de Felipe IV. Madrid, 1983, pág. 186 
preciso hacer también algunas matizaciones: en primer lugar, Murcia y Lorca contribuian además con 370 y 130 fanegas de trigo, respectivamente (en el caso de Murcia se añadían asimismo 200 fanegas de cebada), de las que Cartagena no estaba obligada. En segundo lugar, la superior contribución de la capital era explicable, no sólo por su mayor número de vecinos, sino, sobre todo, por lo extenso de su jurisdicción - lo que las fuentes denominan tierra o partido de Murcia-, formada por: Murcia ciudad y los lugares de Fortuna, La Ñora, La Raya, Puebla de San Pedro, la Puebla Vieja, barrio de Molina, El Palmar, Los Alcázares, Javalí Nuevo y Viejo, Cinco Alquerias, etc., y otras villas del partido como: Aledo con Totana, Ricote, Montealegre, Blanca, Abarán, Ojós, Villanueva, Ulea, Cotillas, Alcantarilla, Lorquí, Campos, Archena y Albudeite. También con el encabezamiento de Murcia se arrendaban las rentas del montazgo de ganados del Obispado de Cartagena, excepto el montazgo de la ciudad de Lorca y su tierra. Cartagena, por contra, sólo tenía en su jurisdicción el lugar de Fuente Álamo, que compartía con Lorca y Murcia, ya que los Alumbres se habían despoblado.

Es evidente que Cartagena fue la peor tratada del realengo murciano -que en su conjunto también salió mal parado, con excepciones como la

FIG. 1. EVOLUCIÓN DE LAS ALCABALAS EN EL REALENGO MURCIANO (1587-1650)

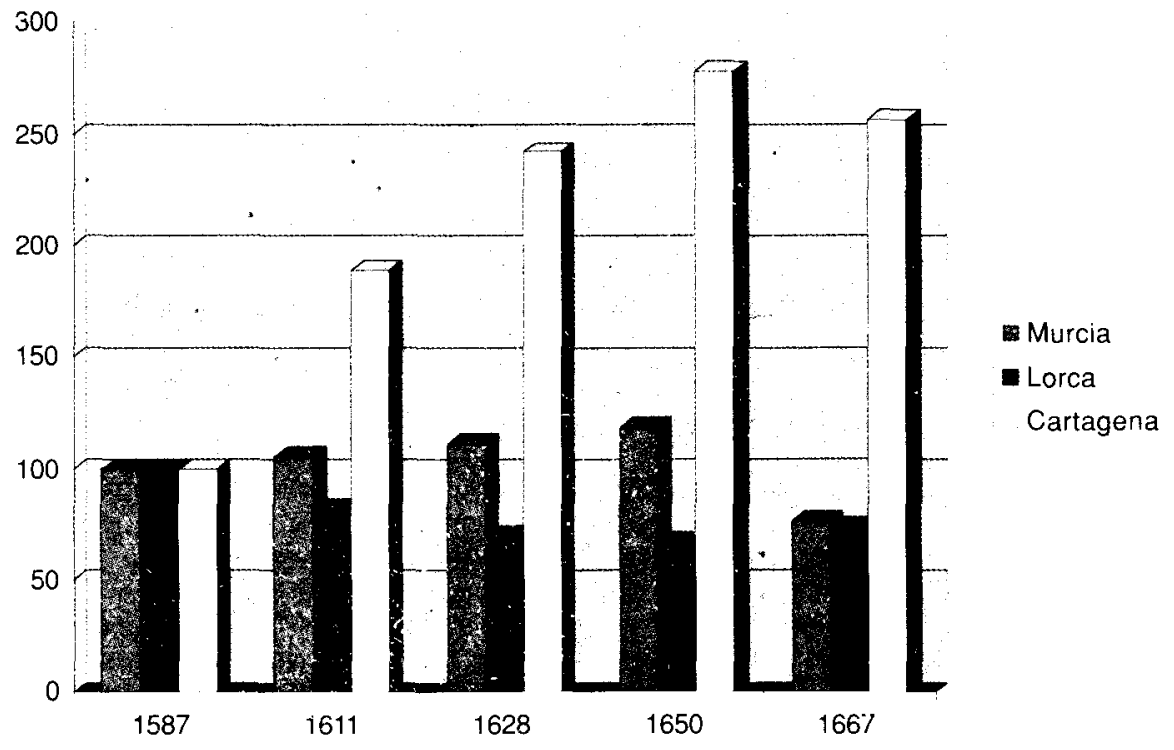

(*) Indice $100=1587$. 
de Lorca-, probablemente porque, como señalaba Francisco Meneses, representante de Cartagena ante el Consejo de Hacienda, "como los lugares de puerto de mar tienen fama de ricos, por el trato y comercio, y al Consejo de Hacienda le avian hecho creer que le valdrían (las nuevas alcabalas) 200.000 ducados, no acababa de tomar resolución" ${ }^{7}$. Pero si la idea del Consejo de Hacienda era de que las ciudades portuarias tenían fama de ricas por el comercio, también podemos encontrar excepciones y además muy significativas: Cádiz, espejo del comercio con las Indias, que en 1587 tenía un encabezamiento de alcabalas de 2.814 .000 maravedíes, le fue incrementado su valor hacia 1611 hasta 3.106.210 maravedies (sólo $10,38 \%$, mientras que Cartagena lo hace en un $184,83 \%)^{8}$. Otros puertos próximos como Almuñécar, Motril, Salobreña y Almería contribuian con caritidades muy pequeñas: Almería, por ejemplo, que en 1587 pagó 352.489 maravedíes, incrementó sensiblemente su aportación en 1611 a 650.00 maravedies, entrando en su partido cinco villas y siete lugares. Málaga constituía la excepción con 8.555.777 maravedíes en 1587 y 18.406.124 en 1611, pero también es verdad que poseía un extenso territorio, fértil y rico, con grandes producciones de vino, aceite, pasa, azúcar, etc., además se sumaban a ella unas crecidas tercias reales ${ }^{9}$.

\section{MONEDA FORERA Y SERVICIO ORDINARIO Y EXTRAORDINARIO}

Entre las rentas tradicionales más conocidas y que afectaban a la mayor parte de los vecinos del reino de Murcia, en tanto que eran considerados "pecheros", es decir, gente no ennoblecida, se encontraban el servicio ordinario y extraordinario y la moneda forera. Ambos tenían la particularidad de ser impuestos personales, que afectaban directamente al cabeza de familia o, en ausencia de éste, a la viuda con hijos. Eran ade-

Archivo Municipal de Cartagena (AMC). AC. cap. 6-iX-1618.

AGS, Cont. Girles., legs. 3896 y 3890.

El partido de Málaga estaba formado en 1611 por la ciudad de Málaga, 18 villas y 3 lugares (AGS, Cont. Grles. leg. ${ }^{\circ}$ 3.890). En cuanto a sus habitantes, ya en 1561 poseía 3.357 vecinos, frente a los 895 que tenía Cartagena en 1560 -relación de 3,75 a 1-. Además las tercias de Málaga, al igual que el reino de Granada, tenían una gran importancia relativa: en 1547-56, por ejemplo, el valor de sus tercias era aproximadamente la tercera parte del precio del encabezamiento, llegando al $40 \%$ en 1557-61 (ULLOA, M., La Hacienda Real..., págs. 23-26 y 228). Es evidente que, a pesar de todo, también estuvo fiscalmente mal tratada, lo que viene a corroborar lo que anteriormente dijimos respecto a la presión fiscal soportada por Andalucia y Murcia, cuyo estudio ofrece una perspectiva muy interesante para posteriores trabajos de conjunto. 
más de rancia solera, pues tanto uno como otro hundían sus orígenes en el pasado bajomedieval.

La MONEDA FORERA en términos fiscales era un tributo más simbólico que efectivo. Se pagaba exclusivamente por los vecinos pecheros cada siete años en señal de vasallaje al Rey. De ahí que, como señala Domínguez Ortiz, perdurara; pues, aunque su producto llegó con el tiempo a ser insignificante -20.000 ducados cada 7 años-, existía cierto interés por los vecinos ahidalgados en hacerse constar por escrito en los padrones que para su efecto se realizaban ${ }^{10}$.

La contribución personal era prácticamente ridícula pues se limitaba a una simple moneda, que podía ser de 8 ó 16 maravedíes de moneda vieja o nueva, excepto en el reino de León, donde se pagaba 6 ó 12 maravedíes ${ }^{11}$. Cartagena, por ejemplo, estaba privilegiada por facultad real, según reza en el padrón de 1638 , «... para la exención de 200 casas de veçinos della, demás de los hombres nobles y todos los extranjeros que vivieren en ella...". Esta anotación del padrón se refiere concretamente al privilegio concedido por Juan I en Torrijos, el 15 de enero de 1384, en el que se concedía franqueza de moneda a los 160 vecinos que vivian en Cartagena y a los 40 primeros que vinieran a vivir a ella: facultad que hizo extensa a todos los vecinos que la ciudad tuviese en adelante. Por tanto, Cartagena estuvo exenta, al igual que Jaén y otras ciudades, del pago de este impuesto ${ }^{12}$.

EI SERVICIO ORDINARIO Y EXTRAORDINARIO, a diferencia de la moneda forera, tenía por característica ser un ingreso suplementario y temporal, destinado a ayudar ocasionalmente al Rey a salir de dificultades financieras. Por consiguiente, debía superar el trámite de las Cortes para su aprobación por el Reino ${ }^{13}$.

Para su recaudación se llevaban a cabo sisas sobre ciertos artículos de consumo, como la carne y el vino, aunque a veces se abonaban de los mismos "propios» municipales. Este es el caso de Cartagena, puesto que según la averiguación sobre alcabalas de 1560 «...no ay diuision de hidalgos ny pecheros, porque el seruicio que la çibdad paga a Su Magestad

10 Dominguez Ortiz, A., Politica y Hacienda... ob. cit, pág. 196.

AMC, Caja 247, exp. 18.

12 AGS, Mercedes y Priv., leg. 274 , fol. ${ }^{\circ} 32$. Se conservan en el AMC varios padrones de moneda forera del siglo XVIt, de valor excepcional para los estudios sociodemográficos. Dichos padrones son los de 1621, 1626, 1634, 1638, 1646 y 1663. Para el caso de Jaén, véase L. CoRONAS TEJADA, Jaén, siglo Xvil. Jaén, 1994, pág. 466. 


\section{CUADRO 2}

Servicio ordinario y extraordinario. Reino de Murcia. Repartimiento de 1607 (en maravedies)

\begin{tabular}{lclc}
\hline \multicolumn{1}{c}{ Localidad } & Contribución & \multicolumn{1}{c}{ Localidad } & Contribución \\
\hline Murcia, ciudad. & 1.435 .552 & Albudeite. & 43.587 \\
Concejos de su tierra (1) & 317.682 & Archena. & 49.338 \\
Lorca, ciudad. & 937.611 & Ricote. & 71.134 \\
Lugares de su tierra (2) & 218.850 & Villanueva. & 39.198 \\
Cartagena, ciudad. & 468.880 & Uléa. & 23.207 \\
Fuente Álamo (Cartagena) & 27.090 & Ojós. & 44.041 \\
Aledo, con Totana. & 235.536 & Blanca. & 97.770 \\
Abanilla. & 152.000 & Abarán. & 64.916 \\
Pliego. & 120.625 & Cieza. & 166.180 \\
Mula, sin La Puebla. & 422.871 & Villena. & 350.677 \\
La Puebla de Mula. & 18.462 & Yecla. & 329.334 \\
Librilla. & 77.943 & Chinchilla y aldeas. & 290.137 \\
Alhama. & 105.640 & Albacete y aldeas. & 658.218 \\
Molina. & 40.710 & Hellin. & 390.330 \\
Campos. & 24.217 & Calasparra. & 217.489 \\
Alcantarilla. & 116.689 & Caravaca. & 846.651 \\
Alguazas. & 79.456 & Moratalla. & 478.566 \\
Ceutí. & 39.198 & Cehegin. & 568.167 \\
Lorqui. & 23.761 & Fortuna. & 85.662 \\
Torre de Cotillas. & 30.470 & & \\
\hline
\end{tabular}

Fuente: AMC. Caja 248, n. ${ }^{\circ}$ 3. (1) Javali Nuevo, El Palomar, Aljucer, Alberca, Santaren, Algezares, San Angel, La Nora, Guadalupe, Javalí Viejo y Espinardo. (2) Huercal, parte Fuente Álamo, Almazarrón y Casas de Alumbres.

se paga de propios de conçejo y sisas y ympusiçiones que tiene en los que sacan pescado del puerto de la dicha çibdad y los vezinos no pagan cosa alguna de lo cual pareçe estar relevados.... ${ }^{14}$.

Esta situación de estancamiento recaudatorio se mantuvo prácticamente inalterable en el reino de Murcia durante el resto del siglo xvi y a lo largo de todo el siglo XVII, donde la tendencia a la petrificación fue la nota predominante sobre todo a partir de 1591. De hecho, si comparamos las cuotas aportadas en los repartimientos de 1607 y 1654 sólo varían levemente Murcia (10.000 mrs.), Lorca (4.000 mrs.), Cartagena (16.000 mrs.), Caravaca $\left(6.000 \mathrm{mrs}\right.$.) y Moratalla $\left(6.000 \mathrm{mrs}\right.$.) ${ }^{15}$.

13 UlloA, M., La Hacienda..., op. cit., págs. 467-68.

14 AGS, C. $\vee \mathrm{JH}$, leg. ${ }^{\circ} 37$, tol. 47.

15 Archivo Municipal de Murcia (AMM), Caja 18, n. 45 . La pequeña subida de Lorca fue compensada con un descuento de 19.856 maravedies en los lugares de su tierra. 
La lectura y análisis del cuadro número 2 aporta algunas conclusiones muy interesantes:

- Reparto desigual de la carga tributaria: las ciudades y tierras de Murcia y Lorca cargan con la mayor parte de este impuesto personal (el $30 \%$ de él).

- Cartagena se beneficia en demasía de la naturaleza medieval de este tributo, cuya cuantía se estanca en el siglo XVI, precisamente cuando esta ciudad experimenta un boom económico y demográfico.

- La aportación lorquina (el 12\%) está claramente desproporcionada, no ajustándose a su evolución socio-económica en el período de los Austrias.

- En comparación a otros tributos (alcabalas, tercias, millones...), la participación de la ciudad de Murcia y su tierra es relativamente escasa (un $18 \%$ del total).

- Las encomiendas santiaguistas hacen honor a la importancia que tuvieron en el tránsito de la Edad Media a la Moderna aportando más del $22 \%$ de la contribución del reino.

- El antiguo marquesado de Villena representa una contribución (sin Almansa) del $17,4 \%$ del total del reino de Murcia, conservando la posición destacada de tiempos anteriores (hecho que les perjudica, como vimos con Lorca).

Pero volviendo a Cartagena, sorprende curiosamente el comportamiento diferencial entre ambos siglos en lo que a la evolución de las contribuciones se refiere. En este sentido, los datos arrojados por diferentes fuentes nos permiten trazar la línea general de crecimiento de esta renta ${ }^{16}$, tal y como podemos apreciar en el cuadro n. ${ }^{\circ} 3$ :

CUADRO 3

Evolución del servicio ordinario y extraordinario en Cartagena (1515-1654)

\begin{tabular}{ccc}
\hline Años & Valor (en mrs.) & Índice \\
\hline 1515 & 12.773 & 100,00 \\
1518 & 18.138 & 142,00 \\
1526 & 25.960 & 203,24 \\
1532 & 26.600 & 208,25 \\
\hline
\end{tabular}

16 Para el periodo 1515-1548, véase V. Montojo, El Siglo de Oro en Cartagena (1480-1640). Murcia, 1993, pág. 341. Para 1560-1584, AGS, EMR, legs. 445, 482, 502 y 521. Por último, para la etapa 1607-1654: AMC, Caja 248, exp. 3; caja 113, exp. 27; Ac. cap. 1640-42, fol. 226, y AMM, caja 18, n. ${ }^{\circ} 45$. 


\section{CUADRO 3}

Evolución del servicio ordinario y extraordinario en Cartagena (1515-1654) (continuación)

\begin{tabular}{ccc}
\hline Años & Valor (en mrs.) & Indice \\
\hline 1541 & 33.300 & 260,71 \\
1548 & 51.450 & 402,80 \\
1560 & 143.750 & $1.125,42$ \\
1566 & 229.001 & $1.792,85$ \\
1584 & 320.440 & $2.508,72$ \\
1590 & 325.525 & $2.548,53$ \\
1607 & 468.880 & $3.670,86$ \\
1615 & 468.880 & $3.670,86$ \\
1640 & 468.880 & $3.670,86$ \\
1654 & 484.880 & $3.796,13$ \\
\hline
\end{tabular}

De la lectura de las cifras del cuadro n. ${ }^{\circ} 3$ pueden observarse dos datos claramente significativos: en primer lugar el ascenso vertiginoso de la contribución por este concepto a lo largo del siglo XVI (multiplica su valor por $25,5)$, lo cual tiene que ver con lo que señalaba Fortea sobre su utilización para sufragar los gastos derivados de las guerras de los Austrias Mayores y que coincide plenamente con esa centuria. En segundo lugar, la repercusión directa que sobre este viejo tributo tuvo la creación de los millones al final del reinado de Felipe II, cuya suficiencia recaudatoria - una vez perpetuados esos millones- provocó su congelación, quedando anquilosado desde 1591 en 454.000 .000 de maravedíes para toda Castilla, con insignificantes subidas para algunas ciudades del reino de Murcia, de las que ya hemos hablado. Hay que decir en este sentido, que la herencia medieval de esta renta benefició a Cartagena en relación a otras localidades del reino de Murcia, no correspondiéndose realmente con el crecimiento demográfico y económico experimentado por esta ciudad en los siglos XVI y XVII.

\section{LAS NUEVAS FIGURAS TRIBUTARIAS DEL REINADO DE FELIPE IV}

El siglo XVII y especialmente el período que coincide con el reinado de Felipe IV (1621-1665), será testigo del nacimiento de nuevas rentas y fuentes de ingresos, que sin constituir un peso cualitativo enorme, si vinieron a complementar el aumento desmesurado de las tradicionales, sobre todo de los servicios de millones y alcabalas. Sin duda, será la propia coyuntura bélica internacional la que marque la pauta a seguir, esta- 
bleciendo diversos ritmos de crecimiento en la presión fiscal, transmitidos ipso facto a las ciudades a través de diferentes vías recaudatorias.

Constituían, por tanto, recursos extraordinarios a los que prácticamente nadie escaparía, ni individuos, ni instituciones, actuando como otro factor descapitalizador más. Entre los varios que afectaron al reino de Murcia, nos centraremos - debido a su repercusión social y económica- en la venta de cargos y oficios y las annatas de mercedes y juros.

Entendemos por DONATIVOS un regalo, una dádiva que las instituciones y los particulares concedían al Rey en situaciones excepcionales, generalmente en momentos delicados para la Monarquía, motivados por quiebras o por necesidades acuciantes de la guerra, que generosa y voluntariamente entregaban los súbditos como solución momentánea a dichos apremios. Otra cosa muy distinta sería la voluntad de la Real Hacienda en hacer perennes y obligatorios estos recursos, tentación en la que cayó reiteradamente la Corona durante el reinado de Felipe IV y que generó multitud de enfrentamientos con las ciudades y villas del Reino.

La historia de estos donativos se inicia en 1590 tras la concesión por las Cortes del primer servicio de millones a Felipe II. Al distrito murciano le fueron repartidos 11.281 .840 maravedies para ayuda del desastre de la Armada Invencible (motivo de este donativo excepcional) durante el período de 1591-1594 y 11.952.910 para el de 1595-1596 ${ }^{17}$. Cartagena contribuyó en el primer repartimiento con 1.033 .860 maravedies -casi un 10\% del total del distrito- y con 1.640.250 en el segundo, recaudados con el arrendamiento de la almadraba de Cabo de Palos y la imposición de diversas tasas a los artículos de importación y exportación ${ }^{18}$. Murcia, una de las ciudades con voto en Cortes, abonó 1.550 .200 maravedíes anuales en el período de 1595-1596, cantidad relativarmente baja en proporción a su importancia política en el reino.

Institucionalizados los «millones» tras ese primer servicio a Felipe II (se convierten en otra renta más), las necesidades acuciantes provocadas por la guerra demandaron nuevas vías de recaudación bajo la vieja fórmula de la excepcionalidad: surgen así los donativos, un recurso muy utilizado por Felipe IV. En 1624 solicitó el primero, al que el reino de Murcia -como otros ierritorios de Castilla- respondió generosamente, sobre todo tras el

17 Ulloa, M., La Hacienda Real..., pág. 524.

18 AMC, Caja 255, exp. 3. 
ataque de los ingleses a Cádiz al año siguiente ${ }^{19}$. Cuatro años más tarde, en 1629, ante los problemas suscitados con motivo de la guerra de Mantua y la amenaza de una invasión francesa en Italia, el monarca volvió a solicitar un nuevo donativo que ya no fue tan bien recibido, si bien en algunos casos, como el de Cartagena, se aprestaron a colaborar con 16.000 ducados pagaderos en cuatro años y recaudables sobre un pequeño arbitrio de 7 maravedíes/libra en el pescado de la almadraba de Escombreras.

La reiteración de esta práctica en 1632 provocó, como apunta Domínguez Ortiz, que el sistema se desacreditara rápidamente: «la primera vez se aceptó casi con entusiasmo; la segunda con frialdad; la tercera suscitó franca hostilidad..." ${ }^{20}$. Y a éste siguieron los de 1635, 1637 y 1639.

Las cantidades aportadas por el reino de Murcia en 1637 fueron las siguientes:

\section{CUADRO 4}

Donativo de 1637. Reino de Murcia

\begin{tabular}{lrc}
\hline \multicolumn{1}{c}{ Localidades } & Cantidad (reales) & Porcentaje \\
\hline Murcia y Espinardo & 423.133 & 39,9 \\
Huerta de Murcia & 38.839 & 3,2 \\
Cartagena & 124.829 & 11,7 \\
Lorca & 94.473 & 8,9 \\
Albacete & 68.704 & 6,4 \\
Helín y Ontur & 44.715 & 4,2 \\
Almansa & 38.843 & 3,6 \\
Viliena & 36.556 & 3,4 \\
Yecla & 35.575 & 3,3 \\
Tobarra & 29.193 & 2,7 \\
Mula, Cotillas y Archena & 28.562 & 2,6 \\
Jumilla & 22.957 & 2,1 \\
Alhama & 21.735 & 2,0 \\
Cabildo de la Iglesia & 16.500 & 1,5 \\
Calasparra & 13.111 & 1,2 \\
Fuente Álamo & 10.932 & 1,0 \\
Mazarrón & 9.147 & 0,8 \\
Librilla & 5.391 & 0,5 \\
\hline Total del reino & $\mathbf{1 . 0 5 9 . 1 9 5}$ & $\mathbf{1 0 0 , 0}$ \\
\hline
\end{tabular}

Fuente: AGS. Cont. Grales (elaboración propia).

19 AGS, Cont. Grrles., $1 .^{\circ} 116$, del que hablaremos en otro capítulo. Sobre éste se realizó un estudio parcial en Fernández VARGAS, V., "Eibar, León, Ocaña y Cartagena en 1625: un ejemplo de estructuras urbanas peninsulares", en Revista Internacional de Sociologia, n. ${ }^{\circ} 36$; Madrid, 1980, págs. 515-537.

20 Dominguez Ortiz, A., Política y Hacienda..., pág. 283 
Del cuadro anterior podemos extraer algunas conclusiones importantes:

- Murcia y su huerta representan el $43,2 \%$ de la contribución del reino, lo que nos da una idea clara, por un lado, del peso económico de la capital y su hinterland, con un enorme potencial agrario (pleno auge del cultivo de la seda), y por otro, de la necesidad de avalar su papel de ciudad con voto en Cortes (importante lastre).

- Cartagena, consolidada su posición como segunda ciudad más importante del reino, no contribuye en este donativo con una cantidad proporcional a su capacidad comercial, posiblemente por la escasa colaboración de este sector tan castigado (su aportación es 3,6 veces inferior a Murcia y su huerta).

- Lorca, con un escaso $8,9 \%$, ha perdido buena parte de su protagonismo y se encuentra inmersa en una fuerte crisis anunciada décadas antes. Aunque tiene más población que Cartagena, su ímpetu económico ha descendido notablemente.

- Las comarcas albaceteñas, con Villena, han perdido buena parte del peso económico que tenían en el reino murciano a comienzos de la Edad Moderna, señal inequívoca del basculamiento hacia la periferia del reino.

- El resto de villas murcianas (Yecla, Mula, Jumilla...), sin Caravaca y Moratalla, parecen amortiguar bien los sintomas de la crisis, consolidando sus poblaciones.

Dos años después, el donativo de 1639 se justificaba por el accidente en la invernada de los galeones de la flota de Indias, con el cual se habían dejado de percibir 1.400 .000 ducados que se debían a los prestamistas de la Corona. Sin más dilación se pidieron 550.000 ducados a las ciudades y villas castellanas por vía de "préstamo», de los cuales fueron repartidos 4.000 ducados al corregimiento de Murcia, Cartagena y Lorca. A Cartagena, por ejemplo, le tocaron 1.200 (el 30\%), aunque según se desprende del acta capitular de 29 de marzo de 1639, los mercaderes, regidores y jurados no estaban dispuestos a pagar más de 300 . En vista de ello, el corregidor devolvió a la ciudad la lista de donantes, forzándole a pagar, como mínimo, 1.000 ducados. Pero el Concejo daba largas, pidiendo que «el donativo sea voluntario y no se les exija más a unos mercaderes que están muy gravados con pechos, imposiciones y otras cargas y donativos..." ${ }^{21}$.

\footnotetext{
21 AMC, Ac. cap. 29-III-1639.
} 
Todavía a mediados de diciembre de 1640 no se había satisfecho la cantidad repartida, cuyo vencimiento estaba fijado para fin de ese mes ${ }^{22}$.

El ejemplo de Cartagena nos ilustra suficientemente de la situación de un reino murciano sumido en una profunda crisis, en la que el despoblamiento, el abandono de los campos y falta de actividad en el puerto de Cartagena (el auténtico motor de la economía regional) no eran sino las más claras evidencias; a ellas se sumaría de forma traumática la terrible epidemia de peste de 1648 con la que se tocó fondo en el período más álgido de la depresión de mediados del XVII. Como ajenos a este problema, desde Madrid no eran conscientes de la situación desesperada del reino, por esc continuaron lloviendo las peticiones de donativos: 1643, 1645, 1648, 1649, 1651, 1654, 1659 y 1664.

La muerte de Felipe IV y el inicio de un nuevo reinado, lejos de suponer un alivio para los súbditos, dio continuidad a la política fiscal establecida, repitiéndose las solicitudes de donativos al reino de Murcia. En el de 1670, motivado una vez más por la guerra con Francia, Murcia colaboró con 2.256.000, Cartagena con 771.000 maravedies, y Lorca con 302.000 maravedíes, en un claro síntoma de estancamiento prolongado en este último caso $^{23}$. Donativos que se reiteraron en $1674-75$ y $1676-77$, y ya en la década de los 80 para no hacer fracasar las reformas monetarias de 1680 y 1686, se solicitarian dos nuevas peticiones en 1684 y $1689^{24}$. En los años 90 , por último, los donativos se centraron más en la nobleza y los ministros de los consejos, quienes participaron decisivamente en los de 1690 , 1692 y 1697.

La VENTA DE CARGOS Y OFICIOS fue otro saneado recurso que utilizaron los Habsburgo españoles para obtener caudales con los que suplir el déficit del tesoro. Así, todo un capital de empleos, destinos y cargos

22 Puesto que aunque «todos desean servir a Su Magestad como lo han hecho en todas las ocasiones voluntariamente, pero que por ser los regidores della y sus vezinos muy pobres, sin caudal ninguno, sino tierra de secanos, no han podido cumplir con lo que han prometido servir a Su Magestad, por lo que hay en esta ciudad muchos ejecutores, vendiéndoles sus bienes, causándoles costas y salarios, con que no se consigue el servicio de Su Magestad, sino aprovechamiento de los dichos ministros y oficiales..." (AMC. Ac. cap. 15 XII-1640).

23 Garzón PAREja, M.: La Hacienda de Carlos II. Madrid, 1980, págs. 351-52.

24 El de 1684 se solicitó a los hombres de negocios, por un lado, que debían entregar la suma que estimaran conveniente según sus recursos y, por otro, a los poseedores de cargos públicos, que abonarían un máximo de 40 ducados. Consecuencia directa de ello fue la huida de personas que desempeñaban cargos públicos y multitud de quejas por parte de las ciudades (SÁNCHEZ BeLÉn, J.A., La política fiscal en Castilla durante el reinado de Carlos II. Madrid, 1996, págs. 263-265). 
salieron a la venta al mejor postor, enajenando una buena parte del patrimonio público en manos de particulares con todas las consecuencias políticas y sociales que se derivaron ${ }^{25}$.

En la sociedad del siglo XVI la adquisición de un cargo -municipal, militar o de cualquier otra especie - aportaba, además de la consabida honra social, sobre todo poder. $Y$ desde el poder era fácil a posteriori rentabilizar la inversión. La compra de una regiduría, por ejemplo, se suponía un gasto amortizable, pues la intervención - particularmente interesadaen el Concejo permitía su reembolso más o menos rápido, a costa de la comunidad vecinal, o lo que es lo mismo, de los sectores económicamente más débiles de la población. Se trataba, en consecuencia, de un buen negocio, tanto desde el punto de vista social como económico, de ahí el temprano interés de los grupos enriquecidos por acapararlos, uno de cuyos mejores ejemplos lo tenemos en la propia burguesía mercantil cartagenera ${ }^{26}$.

En Lorca se produjo, entre 1634 y 1636, un incremento súbito del número de capitulares, con la llegada de tres nuevos regimientos acrecentados, cuyo valor de compra fue de 1.050 ducados $^{27}$. En Cartagena, donde los intereses económicos alcanzaban una dimensión internacional (era fundamental el control de los impuestos sobre el comercio para lograr la exención total o parcial), la pertenencia a la oligarquía dirigente era una cuestión trascendental. De ahí que el acceso a las regidurías por parte de los mercaderes extranjeros se iniciara muy pronto: el primero que comienza esta práctica en Cartagena fue el poderoso mercader bretón Julián

25 Sobre este tema véase: Dominguez Ortiz, A., «La venta de cargos y oficios públicos en Castilla y sus consecuencias económicas y sociales", en Anuario de Historia Económica y Social, n. ${ }^{\circ}$ 3, 1970; TOMÁS Y VALIENTE, F., “La venta de oficios de regidores y la formación de las oligarquías urbanas en Castilla (siglos XVII-XVIII)", Actas de las I Jornadas de Metodología Aplicada de las Ciencias Históricas, Santiago de Compostela, 1975, t. III; CuARTAS RIVERO, M., «La venta de oficios en Castilla-León en el siglo Xvi», en Hisparia, n. ${ }^{\circ}$ 158, 1984; LemEUNIER, G., “Hacienda Real y poderes locales en la Castilla del Antiguo Régimen: las enajenaciones de la Corona", en Actas del I Symposium Internacional Estudio y Fiscalidad en el Antiguo Régimen, ed. de C.M. Cremades, Murcia, 1989; MENÉndez GonzALEZ, A., "La venta de oficios públicos en Asturias en los siglos XVI y XVII" en Boletín del Instituto de Esiudios Asturianos, vol. XXXVIII, n. ${ }^{\circ} 112,1984$, y Montojo Montoso, $V$., "La formacion de la oligarquía urbana de Cartagena a principios del siglo XVI", en Gestae, n 1 (1989), págs. 53-66.

26 Sobre este tema véase mi libro reciéntemente publicado Velasco HeRnÁndez, F., Auge y estancamiento de un enclave mercantil en la periferia. El nuevo resurgir de Cartagena entre 1540 y 1676. Murcia, 2001, págs. 373-453.

27 Robledo DEL PrAdO, M. L., "Sobre ventas de oficios, regidores y otras cuestiones en Lorca a comienzos del xv\|", en Estado y Fiscalidad en el Antiguo Régimen (C. Cremades Griñán, ed.). Murcia, 1988, págs. 214-215. 
Jungue, que hacia 1590 compró una regiduría al Rey por 1.200 ducados, añadiéndosela al título de capitán que ya poseía. Tras su muerte en 1600 , la asoció por vía de mayorazgo a su primogénito Francisco Jungue y Bolea. A este siguió pocos años después otro acaudalado mercader, el genovés Pedro Francisco Panesi, quien conservó la regiduría hasta su muerte en 1608, al igual que el también comerciante ligur Gregorio Monleón ${ }^{28}$.

Precisamente en esta cuestión se había producido un precedente significativo en la capital del reino murciano en 1589, cuando la Corona para hacer frente a sus endémicos problemas financieros había vendido 9 juraderías ${ }^{29}$. En el caso de Cartagena, ya en la segunda década del siglo XVII, se producen nuevas adquisiciones de regidurías por parte de los mercaderes genoveses Jacomo Corvari, Franco Digueri y Octavio Corvari. También hacia 1619 el poderoso e influyente hombre de negocios Vicente Imperial adquirió un nuevo título de regidor por 2.300 ducados, doblando la cantidad pagada 30 años antes por Julián Jungue. Como puede verse, las regidurías cartageneras eran cargos apetecidos que se cotizaban al alza. También adquirieron oficios capitulares los negociantes genoveses afincados en Cartagena, Jusepe Ansaldo y Jacome Rato.

Hacia 1630 se cotizaba una regiduría murciana en 6.500 ducados, en 3.808 ducados las de Cartagena y en 1.050 ducados las de Lorca - tal como podemos ver en el cuadro $n .^{\circ} 5$-; y hasta 8.000 ducados llegaron a ofrecerse por la compra de uno de estos oficios en Murcia ${ }^{30}$. En 3.500 ducados fue valorado en 1634 el que poseía Juan Bautista Preve, vecino de Cartagena y señor de Cúllar. En esta fiebre de ventas, la concesión del servicio de 9 millones en plata por las Cortes a finales de 1635 supuso, además de nuevos arbitrios, la aplicación a éste del valor de un regimiento acrecentado que cada ciudad habría de comprar al Rey. El Concejo cumplió su parte adquiriendo la regiduría, pero no así la Corona, ya que la había entregado a Nicolás Interiano, sin consultar con el Concejo, que puso rápidamente pleito sobre este asunto ${ }^{31}$. Como Cartagena, Yecla oponía una frontal resistencia a la venta indiscriminada de regimientos acre-

28 Velasco HeRnANDEZ, F., “Lazo familiar, conexión económica e integración social. La burguesía mercantil de origen extranjero en Cartagena», en Congreso Internacional Historia de la Familia. Nuevas perspectivas sobre la Sociedad Europea. Murcia, 1998, t. IV, págs. 219-237.

29 Guiliamón Álvarez, F. J./Ruiz IBÉNiez, J. J./Garcia-Hourcade, J. J., La Corona y los representantes del reino de Murcia (1590-1640): necesidad, negociación, beneficio. Murcia, 1995, pág. 11.

$30 \quad$ lbidem, pág. 55.

31 AMC, Ac. cap. 26-04-1636. 
CUADRO 5

Precios de las regidurias en algunas ciudades españolas (Valor en ducados)

\begin{tabular}{crc}
\hline Ciudades & $\mathbf{1 5 5 7}$ & $\mathbf{1 6 3 0}$ \\
\hline Almería & 500 & 1.360 \\
Cádiz & 600 & 4.500 \\
Cartagena & 500 & 3.808 \\
Granada & 2.670 & 8.000 \\
Jaén & 1.300 & 3.700 \\
Jerez & 1.600 & 4.000 \\
Lorca & 500 & 1.050 \\
Madrid & 1.000 & 11.000 \\
Málaga & 500 & 11.000 \\
Murcia & 1.200 & 6.500 \\
Sevilla & 3.200 & 8.000 \\
Toledo & 1.800 & 4.000 \\
\hline
\end{tabular}

Fuente: Gelabert, J.E., La bolsa del Rey. Rey, reino y fisco en Castilla (1598-1648). Madrid, 1997, págs. 165-167.

centados y así lo dejaba patente en una carta dirigida en 1630 a los representantes murcianos en Cortes ${ }^{32}$.

Pero no sólo las regidurias, también otros cargos fueron objeto de atención por ciertos individuos con intención de medrar. Quizás el caso más ilustrativo en este sentido sea el oficio de alguacil mayor perpetuo de Cartagena, adquirido por Vicente Imperial en 1632 por 6.000 ducados ${ }^{33}$, y que llevaba aparejado altas preeminencias en el Concejo que el resto de regidores no estaban dispuestos a tolerar. Desde esa fecha el cabildo no cejó en su empeño de anular la existencia de tal oficio, primero mediante pleito ante el Real Consejo Supremo de Castilla y, por último, admitiendo su incapacidad, por medio de la compra directa al afectado en $9.000 \mathrm{du}$ cados, pagando a la Real Hacienda 2.000 ducados de la media annata, conducción del diriero a la Corte y derechos de los despachos y agentes. Teniendo en cuenta la infiación de la época, todavía resultó barato en

32 AMM, Ac. Cap. 1629, sesión de 15-1-1630.

33 Ochomil ducados según Gelabert (Gelabert, J. E., La bolsa del Rey..., pág. 395). Las preeminencias aludidas eran las siguientes: primera voz y voto en el Concejo, asiento en el ayuntamiento y entrar en el mismo con vara y espada. Podía también nombrar teniente y la mitad de los alguaciles que solían nombrar los corregidores, llevando para sí la mitad de las décimas de ejecución y demás réditos pertenecientes a este oficio (AMC, Ac. cap. 5-V-1639). Por este mismo cargo se habían ofrecido en Lorca tres años antes 5.000 ducados (ROBLEDO DEL PRADO, M.L., «Sobre ventas de oficios..., pág. 214). 
comparación a los 25.000 ducados que la ciudad tuvo que desembolsar en 1606 por el oficio de alcalde mayor de sacas y cosas vedadas ${ }^{34}$.

En Cartagena, como en otras partes del reino, se vendían desde los oficios más sencillos (escribanos, capitanes, etc.) hasta los más ostentosos, como el de cónsul de todas las naciones, que recaía en esta época en Juan Bautista Lamberto; y si no, se creaban nuevos: escribano de millones (valorado en 11.000 reales, más 1.000 reales de guantes y la annata correspondiente), escribano de despacho de la barrilla (11.000 reales, más 1.000 de guantes y la annata) o corredor de fletes de navíos, oficio con el que se presentó Pedro Antonio Madona en el cabildo de 25 de septiembre de 1640. En Lorca se vendieron con este mismo fin el oficio de alcalde provincial de la hermandad, algunas juraderías, escribanías y depositarías generales ${ }^{35}$.

La MEDIA ANNATA de todos los oficios, gracias, mercedes y honores, introducida en 1631, obligaba al poseedor de uno de estos títulos de nombramiento regio a pagar a Hacienda la mitad de la renta con la que estaban dotadas en el primer año de ejercicio. Pero sólo se exigía íntegra cuando el cargo era vitalicio y se rebajaba al diezmo en caso de ser anual, y al cuarto cuando era por 3 años. Nadie escapaba a ella, incluso los grandes títulos, tanto de nueva creación como por herencia. Se aplicaba también en los exámenes de artesanos o de cualquier actividad que exigiese licencia ${ }^{36}$.

Continuando con el ejemplo de Cartagena, el importe de este nuevo tributo fue aplicado, junto con otros, al donativo de 1629. Por él sabemos que un regidor pagaba por la perpetuación de su cargo 1.500 reales -casi todos los abonaron en 3 plazos-; un escribano, 770 reales (1.375 si era de nueva compra); y una facultad de mayorazgo 1.000 reales. También pagaba el cónsul general y todos los demás oficios del Concejo, como jurados, mayordomo, etc. ${ }^{37}$.

Con idéntico nombre se denominaba a la rebaja del $50 \%$ de las gratificaciones y rentas vitalicias o juros, que se introdujo como impuesto irregular, primero, y a partir de 1630 , sobre los detentados por extranjeros, y

AMC, AC. cap. 23-X-1640 y caja 160, exp. 15.

Robledo del Prado, M.L., “Sobre ventas de oficios..., págs. 219-225.

Artola, M., La Hacienda del Antiguo Régimen. Madrid, 1982, pág. 103.

Juan Bautista Lamberto, cónsul general de las naciones en Cartagena, habia pagado al Rey por su cargo 680.000 maravedies, de los cuales había entregado a cuenta 135.000 , más otros 238.000 maravedies que le debia la Corona de cierto trigo que le suministró en Málaga (AMC. Caja 111, n. ${ }^{\circ}$ ). 
más tarde también sobre los de los naturales; si bien, a los primeros se les exigía en mayor cantidad (annata entera o media) que a los segundos (un tercio o media). A partir de 1637 cuando la guerra con Francia empezó a hacer mella, se extendió la media annata a todos los juros, convirtiéndose desde entonces en forma habitual de imposición por parte de Hacienda, que descontaba directamente el tanto por ciento acordado de annata en el dinero a pagar en concepto de juros. La aplicación de estas annatas continuó durante el reinado de Carlos II, creciendo su importe nominal de forma progresiva, al tiempo que se recortaba el valor de los juros a la mínima expresión. Veamos como ejemplo final la media annata librada para 1666 sobre los juros situados en diversas rentas del reino de Murcia:

\section{CUADRO 6}

ANNATA de juros situados en diversas rentas del reino de Murcia hacia 1666 (Valor en maravedies)

\begin{tabular}{lr}
\hline \multicolumn{1}{c}{ Concepto } & \multicolumn{1}{c}{ Cantidad } \\
\hline - Juros de alcabalas Murcia y su partido & 4.500 .000 \\
- Primer 1\% de Murcia & 600.000 \\
- Segundo 1\% de Murcia & 600.000 \\
- Juros del Servicio de Millones de Murcia y provincia & 5.480 .000 \\
- Juros de las sisas de 8.000 soldados del R. ${ }^{\circ}$ de Murcia & 500.000 \\
- Servicio ordinario y extraordinario del R. ${ }^{\circ}$ de Murcia & 1.500 .000 \\
- Papel sellado del Reino de Murcia & 670.000 \\
- Renta antigua sosa y barrilla del Reino de Murcia & 700.000 \\
- Alcabalas de Cartagena & 1.200 .000 \\
- Primer 1\% de Cartagena & 170.000 \\
- Segundo 1\% Cartagena & 140.000 \\
- Alcabalas de Lorca & 480.000 \\
- Primer 1\% de Lorca & 80.000 \\
- Segundo 1\% de Lorca & 70.000 \\
\hline
\end{tabular}

Fuente: AGS, CMC, 3. ${ }^{\text {ep. }}{ }^{\text {a. }}$ (elaboración propia).

\section{CONCLUSIONES}

A lo largo de estas páginas hemos realizado una aproximación a la evolución fiscal del reino de Murcia en el siglo xvil, valorando sus antecedentes medievales y del XVI. Se trata de un tema prácticamente inédito en la historiografía murciana del periodo de los Austrias, poco preocupada por esta problemática tan vita! en el devenir económico del sudeste castellano.

Como ha podido verse, la presión fiscal fue constante y en alza a lo largo del Seiscientos, en una trayectoria similar a la trazada por las ciuda- 
des y villas andaluzas. Todas las rentas experimentaron un súbito ascenso, sin embargo, las alcabalas o impuestos sobre las ventas e intercambios tuvieron un protagonismo destacado, en especial en Cartagena, debido a la actividad mercantil de su puerto, y en Murcia, al calor del auge extraordinario del cultivo y explotación de la seda.

Por el contrario, otros antiguos tributos, como la moneda forera y el servicio ordinario y extraordinario acabaron estancándose, sobre todo a partir de la implantación de los «millones» al final del reinado de Felipe II, lo cual benefició a aquellas localidades, como Cartagena, que inician su expansión económica a mediados del siglo XVI. Estos, junto a los cientos, serán objeto de estudio en una posterior investigación, si bien podemos avanzar su influencia claramente nociva sobre las maltrechas economías locales, al disparar hasta límites insospechados los niveles de presión fiscal soportados por los súbditos del reino murciano.

Finalmente nos hemos detenido en el análisis de algunas fuentes nuevas de recaudación creadas por la fiscalidad de guerra de Felipe IV, como los donativos, la venta de cargos y oficios y las annatas de oficios, gracias, mercedes y honores, cuya venta fue ofrecida de forma generalizada al mejor postor, constituyendo un buen negocio para la burguesía mercantil cartagenera y murciana (no así los donativos y las annatas). Fueron recursos alternativos y complementarios de las rentas tradicionales que desvirtuaron totalmente la credibilidad institucional y ahondaron en la crisis general del reino de Murcia y de la propia Castilla. 